\title{
Association of PTPN22 gene polymorphism with non-segmental vitiligo in South Indian Tamils
}

\author{
Kalai Selvi Rajendiran¹, Medha Rajappa ${ }^{1}$, Laxmisha Chandrashekar², D.M. Thappa
}

${ }^{1}$ Department of Biochemistry, Jawaharlal Institute of Postgraduate Medical Education and Research, Puducherry, India ${ }^{2}$ Department of Dermatology, Jawaharlal Institute of Postgraduate Medical Education and Research, Puducherry, India

Adv Dermatol Allergol 2018; XXXV (3): 280-285

DOI: https://doi.org/10.5114/ada.2018.76225

\begin{abstract}
Introduction: Non-segmental vitiligo (NSV) is a depigmentation skin disease with loss of melanocytes in the skin. Aim: To evaluate whether the protein tyrosine phosphatase non-receptor type (PTPN22) single nucleotide polymorphism at $+1858 \mathrm{C} / \mathrm{T}$ had any association with non-segmental vitiligo in South Indian Tamils.

Material and methods: Genomic DNA was extracted using the phenol-chloroform method, and PTPN22 $+1858 \mathrm{C} / \mathrm{T}$ polymorphism was assayed by Taqman 5'allele discrimination assay. Protein levels were quantified by ELISA.

Results: We found that the allelic frequency of variants of PTPN22 (rs2476601) were significantly different between controls and cases showing a vitiligo risk in the South Indian Tamil population. PTPN22 levels were higher in the heterozygous CT genotype in NSV, when compared with that of the major variant CC genotype of rs 2476601 .

Conclusions: This study suggests that the heterozygous CT genotype, of the PTPN22 SNP rs2476601, has a strong risk association with non-segmental vitiligo in South Indian Tamils.
\end{abstract}

Key words: vitiligo, PTPN22, single nucleotide polymorphism, South Indian Tamils.

\section{Introduction}

Non-segmental vitiligo (NSV) is a depigmenting skin disease with loss of melanocytes. Previous reports show that the melanocytes die due to infiltration of T lymphocytes in the perilesional region [1], due to autoimmune mechanisms, where the $T$ lymphocytes recognize the melanocyte antigen. Protein tyrosine phosphatase nonreceptor type (PTPN22) gene is mapped in the chromosomal region 1p13.3-p13.1 coding for the phosphoprotein named lymphoid tyrosine phosphatase (LYP). This intracellular phosphatase acts as a suppressor of C-terminal Src kinase (Csk) that mediates T-cell activation by binding the proline-rich motif of the Src-homology-3 (SH3) domain $[2,3]$. The single nucleotide polymorphism from $\mathrm{C}$ to T allele of PTPN22 causes addition of tryptophan (W), in lieu of arginine (R) and interferes in the binding of phosphatase and Csk resulting in suppression of T-cell activation. In several autoimmune diseases like type 1 diabetes mellitus, rheumatoid arthritis and other dermatological diseases in various populations, a single nucleotide polymorphism of the PTPN22 at C1858T has been shown to have a strong association [4-7].
Similar to other autoimmune diseases, the immune dysregulation in non-segmental vitiligo (NSV) is thought to result from the relationship between genetic and environmental factors that remain largely unworked. Genome-wide association studies have shown that many genetic factors are associated with vitiligo. Hence, analyzing PTPN22 gene polymorphism will further add to the existing knowledge on the autoimmune pathogenesis of vitiligo in South Indian Tamils.

\section{Aim}

The aim of the study was to evaluate whether the protein tyrosine phosphatase non-receptor type (PTPN22) single nucleotide polymorphism at $+1858 \mathrm{C} / \mathrm{T}$ had any association with non-segmental vitiligo in South Indian Tamils.

\section{Material and methods}

Patients and controls recruitment

This was a case-control study involving two hundred and sixty four patients with NSV of Tamil ethnicity and

Address for correspondence: Dr. Medha Rajappa, Department of Biochemistry, Jawaharlal Institute of Postgraduate Medical Education and Research, 605006 Puducherry, India, e-mail: linkmedha@gmail.com Received: 3.02.2017, accepted: 23.04.2017. 
264 age-, gender- and ethnicity-matched controls. All patients with non-segmental vitiligo and aged 18-60 years, without history of other autoimmune disordes were recruited from the dermatology clinic at our hospital, a tertiary-care centre in South India. The vitiligo disease activity index (VIDA) [8] was used to assess the disease activity in patients with NSV. Disease duration, prior therapies, and the detailed family history were recorded. Age- and gender-matched controls of Tamil ethnicity and without family history of vitiligo or of other autoimmune disorders were enrolled in the study.

This project was approved by the Institute Ethics Committee for Human Studies. Informed consent was taken from all study subjects, before enrollment. The study was performed according to the World Medical Association Declaration of Helsinki ethical principles for medical research involving human subjects [9].

\section{DNA extraction and genotyping}

Five milliliters of blood sample was withdrawn from all study subjects. Extraction of human genomic DNA from the blood leucocytes was performed by modified phenol-chloroform method [10]. Purified DNA was quantified using the NanoDrop (ND)-1000 spectrophotometer (NanoDrop Technologies Inc., USA) diluted to $100 \mathrm{ng} / \mu \mathrm{l}$ and stored in Tris-EDTA buffer at $-40^{\circ} \mathrm{C}$. The PTPN22 1858C/T genotypes were identified by Taqman 5' bi-allelic discrimination assay using primers and probes from Applied Biosystems, California, USA, on a Bio-Rad CFX Real-time system (BioRad CFX, California, USA). Plasma PTPN22 was analyzed using ELISA.

\section{Statistical analysis}

Direct gene counting was implied to analyze genotype frequencies in vitiligo patient and control groups. The frequencies of PTPN22 C1858T genotypes and alleles were compared between vitiligo patient and control groups using a chi-square test on $2 \times 2$ contingency tables. Odds ratio (OR), and confidence intervals (Cls) were computed using Graph Pad Prism (Graph Pad Software Inc., San Diego, CA, USA). Genetic model analysis was used to confirm the association of the genotype further. Within the NSV group, the influence of genotypes on the clinical phenotype was assessed by $\chi^{2}$ test. Protein levels of the respective genotypes of SNP among cases was compared by Mann-Whitney $U$ test. The observed allele frequencies in cases and controls were compared with expected frequencies by $\chi^{2}$ test to check for the Hardy-Weinberg equilibrium. Values of $p<0.05$ (two-tailed) was considered as significant.

\section{Results}

A total of 264 non-segmental vitiligo cases and 264 unrelated healthy controls were enrolled in our study.
The demographic and clinical characteristics of the study subjects are shown in Table 1.

PTPN22 displayed a significant deviation from the Hardy-Weinberg equilibrium ( $p<0.05)$. On analysis of association between the heterozygous CT genotype in NSV and controls, we obtained a particularly significant association with NSV risk and noted that those with the CT genotype had a 4.68 times increased OR of having NSV compared to controls ( $p<0.0001)$. Genetic model analysis also confirmed the association of the CT heterozygous genotype in NSV compared to controls (Table 2). We stratified the patients

Table 1. Demographic and clinical characteristics of the study subjects

\begin{tabular}{|c|c|c|}
\hline Parameter & $\begin{array}{c}\text { Non-segmental } \\
\text { vitiligo } \\
(n=264)\end{array}$ & $\begin{array}{l}\text { Controls } \\
(n=264)\end{array}$ \\
\hline \multicolumn{3}{|l|}{ Demographic details: } \\
\hline Male & 133 & 134 \\
\hline Female & 131 & 130 \\
\hline Gender ratio (male : female) & $1: 1$ & $1: 1$ \\
\hline Mean age [years] & $40.34 \pm 14.27$ & $38.20 \pm 11.93$ \\
\hline \multicolumn{3}{|c|}{ Clinical details of non-segmental vitiligo: } \\
\hline Mean VIDA score & $1.96 \pm 1.49$ & \\
\hline $\begin{array}{l}\text { Mean duration of the disease } \\
\text { [months] }\end{array}$ & $63.60 \pm 86.82$ & \\
\hline $\begin{array}{l}\text { Mean age of onset of disease } \\
\text { [years] }\end{array}$ & $33.58 \pm 15.80$ & \\
\hline Family history of vitiligo, $n(\%)$ & $41(15.53)$ & \\
\hline $\begin{array}{l}\text { Personal history of thyroid } \\
\text { disorder, } n(\%)\end{array}$ & $11(4.16)$ & \\
\hline $\begin{array}{l}\text { Early-onset vitiligo } \\
\text { (age < } 30 \text { years), } n(\%)\end{array}$ & $107(40)$ & \\
\hline $\begin{array}{l}\text { Late-onset vitiligo } \\
\text { (age > } 30 \text { years), } n(\%)\end{array}$ & $157(60)$ & \\
\hline Active vitiligo, $n$ (\%) & $200(76)$ & \\
\hline Stable vitiligo, $n(\%)$ & $64(24)$ & \\
\hline Koebner phenomenon, $n$ (\%) & $46(17)$ & \\
\hline Trichrome sign, $n(\%)$ & $53(20)$ & \\
\hline Leukotrichia, $n$ (\%) & $6(2)$ & \\
\hline
\end{tabular}

Types, $n$ (\%):

\begin{tabular}{lc}
\hline Vitiligo vulgaris & $125(47)$ \\
\hline Acrofacial & $102(39)$ \\
\hline Mixed & $25(9.5)$ \\
\hline Focal & $8(3)$ \\
\hline Universal & $4(1.5)$ \\
\hline
\end{tabular}


Table 2. PTPN22 (C1858T) genotype and allele frequencies in the study population

\begin{tabular}{|c|c|c|c|c|}
\hline $\begin{array}{l}\text { PTPN-22 } \\
\text { rs2476601 }\end{array}$ & $\begin{array}{c}\text { NSV } \\
(n=264)\end{array}$ & $\begin{array}{l}\text { Controls } \\
(n=264)\end{array}$ & $\begin{array}{l}\text { P-value } \\
\left(\chi^{2} \text { test }\right)\end{array}$ & OR $(95 \% \mathrm{Cl})$ \\
\hline \multicolumn{5}{|l|}{ Genotype: } \\
\hline $\mathrm{CT}$ & 165 & 69 & $<0.0001^{*}$ & $4.68(3.23-6.79)$ \\
\hline $\mathrm{TT}$ & - & 1 & $1.000^{* *}$ & $0.65(0.02-16.15)$ \\
\hline $\mathrm{CC}$ & 99 & 194 & & \\
\hline \multicolumn{5}{|l|}{ Allele: } \\
\hline$T$ & $165 / 528$ & $71 / 528$ & $<0.0001^{\star}$ & $2.93(2.14-3.99)$ \\
\hline C & $363 / 528$ & $457 / 528$ & & \\
\hline \multicolumn{5}{|c|}{ Dominant model analysis: } \\
\hline $\mathrm{CC}+\mathrm{CT}$ & 264 & 263 & $1.000^{\star *}$ & $3.011(0.12-74.31)$ \\
\hline $\mathrm{TT}$ & 0 & 1 & $1.000^{* *}$ & $0.33(0.013-8.19)$ \\
\hline \multicolumn{5}{|c|}{ Recessive model analysis: } \\
\hline $\mathrm{TT}+\mathrm{CT}$ & 165 & 70 & $<0.0001^{\star}$ & $4.62(3.19-6.68)$ \\
\hline $\mathrm{CC}$ & 99 & 194 & $<0.0001^{*}$ & $0.22(0.15-0.31)$ \\
\hline \multicolumn{5}{|c|}{ Co-dominant model analysis: } \\
\hline CT & 165 & 69 & $<0.0001^{\star}$ & $4.71(3.25-6.82)$ \\
\hline $\mathrm{CC}+\mathrm{TT}$ & 99 & 195 & $<0.0001^{\star}$ & $0.21(0.14-0.30)$ \\
\hline \multicolumn{5}{|c|}{ Homozygotic model analysis: } \\
\hline $\mathrm{CC}$ & 99 & 194 & $<0.0001^{\star}$ & $0.21(0.14-0.30)$ \\
\hline TT & 0 & 1 & $1.000^{\star \star}$ & $1.53(0.06-38.04)$ \\
\hline
\end{tabular}

${ }^{*} p<0.05$ considered as significant, ${ }^{* *}$ Fisher's exact test was done as the sample size was less.

based on: (i) constant clinical phenotypes: gender, age of disease onset, family history of vitiligo, type of vitiligo (ii) variable clinical parameter: VIDA score: disease activity.

Influence of the CT heterozygous genotypes on the phenotypic profile of non-segmental vitiligo is shown in Table 3. When we looked for the influence of the CT

Table 3. Influence of the CT heterozygous genotypes on the phenotypic profile of non-segmental vitiligo

\begin{tabular}{lcc}
\hline Variable & \multicolumn{2}{c}{ CC vs. CT genotypes } \\
\cline { 2 - 3 } & $P$-value & OR $(95 \% \mathrm{Cl})$ \\
\hline Males vs. females & 0.39 & $1.29(0.79-2.12)$ \\
\hline Early onset vs. late onset & 0.87 & $1.07(0.64-1.79)$ \\
\hline Family history + vs. family history - & 0.08 & $2.06(0.96-4.41)$ \\
\hline Acrofacial vitiligo type vs. other types & $0.005^{*}$ & $2.22(1.29-3.80)$ \\
\hline Vitiligo vulgaris type vs. other types & 0.50 & $0.81(0.49-1.34)$ \\
\hline Active vitiligo vs. stable vitiligo & 0.18 & $1.54(0.86-2.72)$ \\
\hline${ }^{*} p<0.05$ considered significant. & &
\end{tabular}

genotype in gender of the NSV group $(n=264)$, we did not find any significant difference between females and males. When we checked the association of the CT genotype with the onset of disease, type of disease, we did not obtain any significant effect, except for the acrofacial type of vitiligo with high OR of $2.22(p=0.005)$. When we analyzed the association of genotypes with family history, we found no significant association with $p$-value of 0.08 and OR of 2.06. In case of the association of the genotype with the disease progression, active vitiligo had OR of 1.54 ( $p=0.18$ ) (Table 3$)$.

The median plasma levels of PTPN22 were compared between cases and controls, which showed increased levels in cases compared to controls ( $p<0.001)$ (Figure $1 \mathrm{~A}$ ). On examining the influence of genotypes of rs2476601 on the plasma PTPN22 amongst the cases, we found a significant association with heterozygous CT genotypes ( $p=0.0005)$ (Figure $1 \mathrm{~B})$.

\section{Discussion}

A high frequency of PTPN22 1858C/T genotype has been linked with several autoimmune disorders which 
A

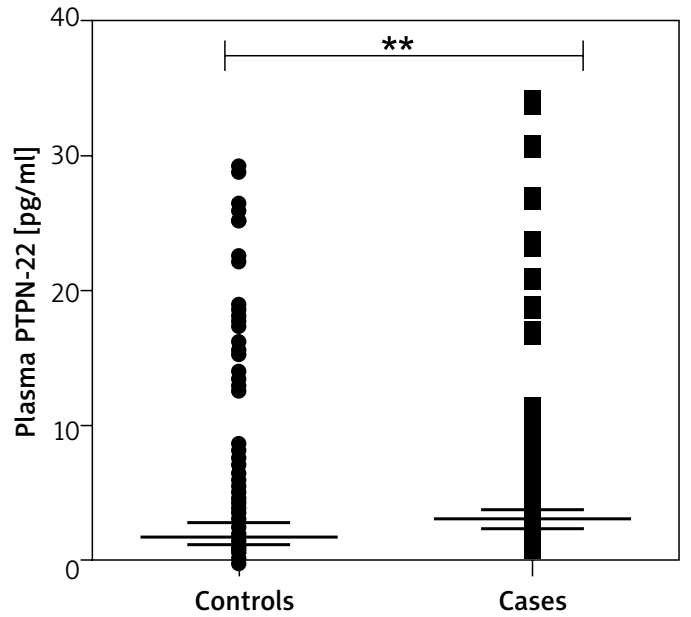

B

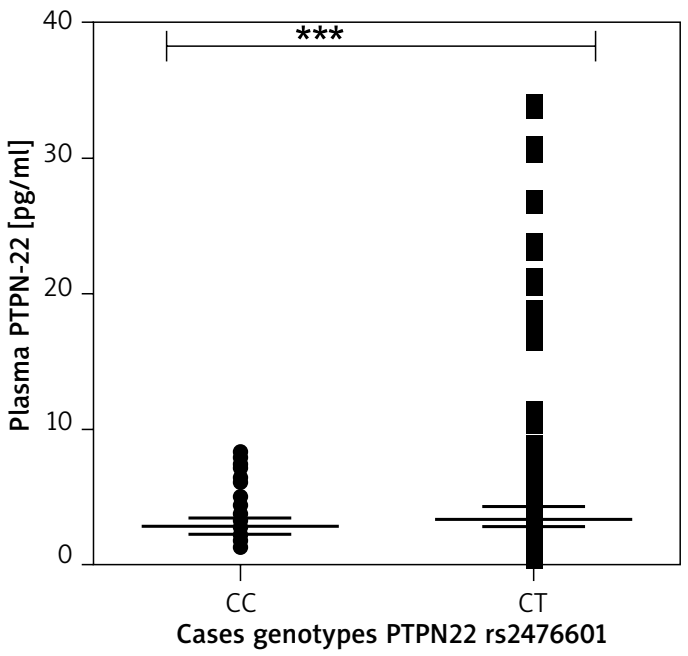

Figure 1. A - Plasma PTPN22 levels in the study population, B - Plasma PTPN22 on genotypes of rs2476601 in cases ${ }^{* *} p<0.0001$ calculated by independent $t$ test, ${ }^{* * *} p=0.0005$ calculated by independent $t$ test.

have T-cell and humoral components [11]. In this study, our interest was to investigate the association between NSV and PTPN22, and we found a frequency of $62 \%$ of the CT heterozygous genotype in the NSV group compared to the control population, which was significantly associated with the risk of being susceptible to vitiligo. Siminovitchet [12] have reported that there is an adverse immune reaction by the $T$ cells against autoantigens after immune stresses. PTPN22 variant is associated with the risk of several autoimmune diseases [13]. We observed that PTPN22 (1858C/T) heterozygous genotype was associated with NSV and this indicates that genetic variants of PTPN22 could add to the immune dysfunction and render vulnerability to the autoimmune mechanism in NSV.
In the current research, we found a significantly higher odds $(O R=4.68)$ in the distribution of the CT genotype between controls and NSV patients, which indicates a predisposition of developing vitiligo in Tamil ethnicity. We found that there is an increased risk of the CT genotype among patients with acrofacial vitiligo, with $\mathrm{OR}=$ 2.22. When we checked for association of the PTPN22 genotypes with the disease activity, active vitiligo had OR of 1.54 ( $p=0.18$ ). The PTPN22 genotypes frequency distribution in our population was not concordant with Hardy-Weinberg equilibrium. This might have occurred due to endogamous marriage in our population. It could also be due to procedural error, which was ruled out by replicating the assay in $30 \%$ of the samples randomly.

Table 4. Association of the PTPN22 gene with vitiligo in other ethnicities

\begin{tabular}{|c|c|c|c|c|c|c|}
\hline References & Ethnicity & Sample size & SNP/rsID & Allele/genotype & $P$-value & Odds ratio $(95 \% \mathrm{Cl})$ \\
\hline \multirow{2}{*}{$\begin{array}{l}\text { Canton et al., } \\
2005 \text { [17] }\end{array}$} & Norwegian & 165 & rs2476601 & $\mathrm{T}$ & 0.006 & $1.82(1.17-2.82)$ \\
\hline & & & rs2476601 & $\mathrm{CT}$ & 0.05 & $1.64(1.02-2.65)$ \\
\hline $\begin{array}{l}\text { Laberge et al., } \\
2008 \text { [20] }\end{array}$ & $\begin{array}{l}126 \text { Caucasian extended } \\
\text { families with multiple } \\
\text { cases of vitiligo }\end{array}$ & 712 & rs2476601 & $\mathrm{CT}$ & 0.024 & $2.35(1.25-4.43)$ \\
\hline \multirow{2}{*}{$\begin{array}{l}\text { Laberge et al., } \\
2008 \text { [21] }\end{array}$} & Romanian & 65 & rs2476601 & $\mathrm{T}$ & 0.0138 & $2.92(1.21-7.03)$ \\
\hline & & & rs2476601 & $\mathrm{CT}$ & 0.036 & $2.69(1.07-6.80)$ \\
\hline $\begin{array}{l}\text { Jin et al., } \\
2010 \text { [19] }\end{array}$ & $\begin{array}{l}\text { European derived white } \\
\text { (CEU) ancestry }\end{array}$ & 1514 & rs2476601 & GWAS & $\begin{array}{l}1.31 \times 10^{-7} \\
(<0.001)\end{array}$ & $1.39(1.01-2.93)$ \\
\hline \multirow{2}{*}{$\begin{array}{l}\text { Garcia-Melendez } \\
\text { et al., } 2012 \text { [18] }\end{array}$} & Mexican & 187 & rs2476601 & $\mathrm{T}$ & 0.047 & $2.25(0.98-5.17)$ \\
\hline & & & rs2476601 & $\mathrm{CT}$ & 0.044 & $2.32(1.00-5.37)$ \\
\hline
\end{tabular}


An in vitro study has shown that T-cells with T-allele may be hyper-reactive, and therefore those with $T$ allele are vulnerable to autoimmunity as the T-allele of PTPN22 shows less affinity with Csk than the C-allele does [14, 15]. In our study, we obtained a strong association with T allele, with OR of 2.93, which would contribute to the autoimmune response in NSV patients. Genetic model analysis also confirms the risk association of $T$ allele with vitiligo in our population. In a meta-analysis by Lee et al. [16], PTPN22 1858 T allele has been shown to have a strong association with a risk of rheumatoid arthritis, systemic lupus erythematosus, Grave's disease, type 1 diabetes and juvenile inflammatory arthritis and a undisruptive effect on psoriasis, inflammatory bowel disease, multiple sclerosis, Addison's disease and celiac disease.

To date, to the best of our knowledge, there are few studies in Indian ethnicity about vitiligo susceptibility and PTPN22 C1858T polymorphism. Recent studies have shown the association of the variants of PTPN22 with vitiligo, in Mexican and Norwegian populations [17, 18]. Our results were concordant with these previous studies which have reported that SNP in PTPN22 genes are susceptibility factors for NSV, conveying that the CT heterozygous genotype would be the predisposing factor for vitiligo susceptibility in different ethnicities worldwide (Table 4).

Genome-wide association studies by Jin et al. [19] have suggested that independent susceptibility loci such as PTPN22 amongst several others are associated with generalized vitiligo. Recent reports have shown that PTPN22 gene was associated with genetic susceptibility to generalized vitiligo [20, 21] (Table 4).

Bottini et al. [22] have shown that heterozygous PTPN22 1858C/T is a risk factor for type 1 diabetes mellitus. Our results showed concordant results with the heterozygous genotype, suggesting that $T$ allele is a risk factor for vitiligo susceptibility. Gjörloff-Wingren et al. [11] have reported that both mouse and human lymphoid tyrosine phosphatase (LYP) inhibit activation of human T cells, along with C-terminal Src kinase (Csk). With an increase in plasma PTPN22 in vitiligo, our results suggest that activated $T$ helper cells could be the reason for the autoimmune mechanism in vitiligo. Attenuated T-cell receptor (TCR) signaling has been an important issue in the origin of autoimmunity. In this regard, the rs2476601 SNP in PTPN22, with substitution of tryptophan reduces TCR signaling which further results in increased phosphatase activity, predisposing to several autoimmune disorders. Thus, the higher plasma PTPN22 levels in cases could also be explained with the fact that there is gain of the mutant function as reported by Vang et al. [23].

From the review by Burn et al. [24], it is evident that PTPN22 represents a candidate gene of autoimmune disease. Our study findings contribute to the current understanding of genetic predisposition of PTPN22 and may be of therapeutic benefit in NSV. In a study by Vang et al. [25], the authors observed that a heterozygous CT individual has an elevated risk of autoimmune disease as compared to those without the heterozygous genotype. Also, the CT genotype is much more frequent than the TT genotype [25]. A recent report by Vang et al. [26] substantiates the claim that the autoimmune-associated LYP with tryptophan at position 620, causes abridged TCRmediated signaling. Thus, imbalanced signalling eventually influence the $T$ cell differentiation, which favors Th1 responses [26].

\section{Conclusions}

Our results suggest that the CT heterozygous genotype of the PTPN22 gene SNP (rs2476601) is strongly associated with a risk of NSV in South Indian Tamils.

\section{Acknowledgments}

Intramural funding from our Institute for this research work is gratefully acknowledged.

\section{Conflict of interest}

The authors declare no conflict of interest.

\section{References}

1. van den Boorn JG, Konijnenberg D, Dellemijn TAM, et al. Autoimmune destruction of skin melanocytes by perilesional T cells from vitiligo patients. J Invest Dermatol 2009; 129: 2220-32.

2. Cohen S, Dadi H, Shaoul E, et al. Cloning and characterization of a lymphoid-specific, inducible human protein tyrosine phosphatase, Lyp. Blood 1999; 93: 2013-24.

3. Cloutier JF, Veillette A. Cooperative inhibition of T-cell antigen receptor signaling by a complex between a kinase and a phosphatase. J Exp Med 1999; 189: 111-21.

4. Zhebrun D, Kudryashova Y, Babenko A, et al. Association of PTPN22 1858T/T genotype with type 1 diabetes, Graves' disease but not with rheumatoid arthritis in Russian population. Aging 2011; 3: 368-73.

5. Torres-Carrillo NM, Ruiz-Noa Y, Martínez-Bonilla GE, et al. The +1858 C/T PTPN22 gene polymorphism confers genetic susceptibility to rheumatoid arthritis in Mexican population from the Western Mexico. Immunol Lett 2012; 147: 41-6.

6. Cénit MC, Márquez A, Cordero-Coma M, et al. Lack of association between the protein tyrosine phosphatase nonreceptor type 22 R263Q and R620W functional genetic variants and endogenous non-anterior uveitis. Mol Vis 2013; 19: 638-43.

7. Chen YF, Chang JS. PTPN22 C1858T and the risk of psoriasis: a meta-analysis. Mol Biol Rep 2012; 39: 7861-70.

8. Njoo MD, Das PK, Bos JD, Westerhof W. Association of the Köbner phenomenon with disease activity and therapeutic responsiveness in vitiligo vulgaris. Arch Dermatol 1999; 135: 407-13.

9. Code N. The Nuremberg Code. Trials War Crim. Nuremberg Mil. Trib. Control Counc. Law 1949; 10: 181-2. 
10. Miller SA, Dykes DD, Polesky HF. A simple salting out procedure for extracting DNA from human nucleated cells. Nucleic Acids Res 1988; 16: 1215.

11. Gjörloff-Wingren A, Saxena M, Williams S, et al. Characterization of TCR-induced receptor-proximal signaling events negatively regulated by the protein tyrosine phosphatase PEP. Eur I Immunol 1999; 29: 3845-54.

12. Siminovitch KA. PTPN22 and autoimmune disease. Nat Genet 2004; 36: 1248-9.

13. Wandstrat A, Wakeland E. The genetics of complex autoimmune diseases: non-MHC susceptibility genes. Nat Immunol 2001; 2: 802-9.

14. Begovich AB, Carlton VEH, Honigberg LA, et al. A missense single-nucleotide polymorphism in a gene encoding a protein tyrosine phosphatase (PTPN22) is associated with rheumatoid arthritis. Am J Hum Genet 2004; 75: 330-7.

15. Hasegawa K, Martin F, Huang G, et al. PEST domain-enriched tyrosine phosphatase (PEP) regulation of effector/ memory T cells. Science 2004; 303: 685-9.

16. Lee YH, Rho YH, Choi SJ, et al. The PTPN22 C1858T functional polymorphism and autoimmune diseases: a meta-analysis. Rheumatology 2007; 46: 49-56.

17. Canton I, Akhtar S, Gavalas NG, et al. A single-nucleotide polymorphism in the gene encoding lymphoid protein tyrosine phosphatase (PTPN22) confers susceptibility to generalised vitiligo. Genes Immun 2005; 6: 584-7.

18. Garcia-Melendez ME, Salinas-Santander M, SanchezDominguez C, et al. Protein tyrosine phosphatase PTPN22 +1858 C/T polymorphism is associated with active vitiligo. Exp Ther Med 2014; 8: 1433-7.

19. Jin Y, Birlea SA, Fain PR, et al. Variant of TYR and autoimmunity susceptibility loci in generalized vitiligo. N Engl I Med 2010; 362: 1686-97.

20. LaBerge GS, Bennett DC, Fain PR, Spritz RA. PTPN22 is genetically associated with risk of generalized vitiligo, but CTLA4 is not. J Invest Dermatol 2008; 128: 1757-62.

21. Laberge GS, Birlea SA, Fain PR, Spritz RA. The PTPN221858C > T (R620W) functional polymorphism is associated with generalized vitiligo in the Romanian population. Pigment Cell Melanoma Res 2008; 21: 206-8.

22. Bottini N, Musumeci L, Alonso A, et al. A functional variant of lymphoid tyrosine phosphatase is associated with type I diabetes. Nat Genet 2004; 36: 337-8.

23. Vang T, Congia M, Macis MD, et al. Autoimmune-associated lymphoid tyrosine phosphatase is a gain-of-function variant. Nat Genet 2005; 37: 1317-9.

24. Burn GL, Svensson L, Sanchez-Blanco C, et al. Why is PTPN22 a good candidate susceptibility gene for autoimmune disease? FEBS Lett 2011; 585: 3689-98.

25. Vang T, Miletic AV, Bottini N, Mustelin T. Protein tyrosine phosphatase PTPN22 in human autoimmunity. Autoimmunity 2007; 40: 453-61.

26. Vang T, Landskron J, Viken MK, et al. The autoimmune-predisposing variant of lymphoid tyrosine phosphatase favors $T$ helper 1 responses. Hum Immunol 2013; 74: 574-85. 